\title{
Do bilingual children lag behind? A study of morphological encoding using ERPs
}

\author{
Harald CLAHSEN* and Anna JESSEN \\ Potsdam Research Institute for Multilingualism, Germany \\ ${ }^{\star}$ Corresponding author: University of Potsdam, Potsdam Research Institute for Multilingualism, \\ Karl-Liebknecht-Str. 24-25, 14476 Potsdam, Germany. Phone: +49-331-9772840; \\ E-mail: harald.clahsen@uni-potsdam.de
}

(Received 20 July 2018; revised 23 January 2019; accepted 1 May 2019)

\begin{abstract}
The current study investigates how bilingual children encode and produce morphologically complex words. We employed a silent-production-plus-delayed-vocalization paradigm in which event-related brain potentials (ERPs) were recorded during silent encoding of inflected words which were subsequently cued to be overtly produced. The bilingual children's spoken responses and their ERPs were compared to previous datasets from monolingual children on the same task. We found an enhanced negativity for regular relative to irregular forms during silent production in both bilingual children's languages, replicating the ERP effect previously obtained from monolingual children. Nevertheless, the bilingual children produced more morphological errors (viz. over-regularizations) than monolingual children. We conclude that mechanisms of morphological encoding (as measured by ERPs) are parallel for bilingual and monolingual children, and that the increased over-regularization rates are due to their reduced exposure to each of the two languages (relative to monolingual children).
\end{abstract}

Keywords: morphology; event-related brain potentials; bilingualism

\section{Introduction}

Does bilingualism delay language acquisition in children? For some researchers, the answer to this question is a clear 'Yes'. Hoff et al. (2012, p. 24), for example, noted that '[...] on average children acquiring two languages will lag behind children acquiring only one [...]' Likewise, Bialystok (2009) pointed out that bilingual children in each of their languages and at all developmental levels lag behind their monolingual peers, which led to language proficiency (as measured in terms of their vocabulary size) firming as 'the bad' of bilingualism (Bialystok, 2009, p. 4) in her well-known triad ('The good, the bad, and the indifferent'). The 'bilingual delay' has been attributed to reduced exposure and use - given that a bilingual child receives less input in each of her languages and practises each of her languages less than a monolingual child. As regards adult bilinguals, a number of studies have reported reduced linguistic performance in

( ) The Author(s) 2019. This is an Open Access article, distributed under the terms of the Creative Commons Attribution licence (http://creativecommons.org/licenses/by/4.0/), which permits unrestricted re-use, distribution, and reproduction in any medium, provided the original work is properly cited. 
each language compared to monolingual speakers, with higher error rates and longer production latencies, for example, in picture naming tasks; see Bialystok (2017) for a recent review. This contrast has been attributed to a bilingual's joint activation of two potentially competing linguistic expressions (one from each language) for naming the same target picture, causing less accurate and slower responses than in monolingual speakers (e.g., Luk, Green, Abutalebi, \& Grady, 2012). It should be noted, however, that evidence for a bilingual delay/deficit comes almost exclusively from measures of LEXICAL SKILL, such as vocabulary size, speed and accuracy of object naming, and word/ non-word discrimination.

Other researchers have taken the bilingual delay/deficit as a myth (e.g., Grosjean, 2010, pp. 178ff), highlighting instead the ease with which young children learn more than one language during childhood. Meisel (2013, p. 70) observed that the simultaneous acquisition of more than one language in early childhood (i) yields linguistic systems that are differentiated from early on, (ii) proceeds through the same sequences as in monolingual children, and (iii) leads to ultimate attainment in each of the languages of multilingual children identical to that of their monolingual peers. These observations have been taken to demonstrate the robustness of the child's ability to learn language irrespective of whether the environment contains one, two, or more languages. It should be noted, however, that the evidence for bilingual first language acquisition being basically identical to monolingual L1 acquisition mainly comes from measures of GRAMMATICAL SKILL, such as the development of grammatical finiteness, agreement, grammatical gender, and related phenomena; see Kupisch (2018).

There is a considerable amount of research that compares linguistic skills and their development in bilingual and monolingual children, and the nature of how they differ (if at all) continues to be a prominent topic in bilingualism research. The controversy seems far from resolved, however; see, for example, Carroll (2017a, 2017b). Against this background, the present study pursues a novel approach to achieve detailed insights into bilingual children's spoken language production, by investigating both their behavioural output and the mechanisms of encoding and planning their productions, the latter by means of event-related brain potentials (ERPs). ERPs represent a continuous series of positive and negative voltage changes in the ongoing electroencephalogram (EEG) and provide a detailed measure of on-line language processing with a temporal resolution in the millisecond range. The linguistic phenomenon we are examining here is inflectional morphology, specifically regular vs. irregular past tense forms in English and corresponding past participle forms in German. In dual-morphology accounts, these linguistic systems have been argued to offer a sharp distinction between lexical and grammatical representations and processes, with irregular forms retrieved from dedicated lexical entries vs. regular forms computed from stems and affixes by grammatical rules; see Clahsen (2006) for review. Thus, from this perspective, studying how bilingual (compared to monolingual) children encode, plan, and produce regular and irregular word forms should help to determine whether there are any delays/deficits of bilingual language production, and if so to what extent lexical and grammatical skills are involved.

\section{Morphological encoding in adults and children}

Models of language production posit a sequence of steps from conceptual encoding via lemma selection, morphological and phonological encoding, and finally motor 
execution and articulation (e.g., Indefrey \& Levelt, 2004). 'Morphological encoding' specifically refers to the planning of inflected or derived word forms prior to speech output. For the adult speaker, many studies have led to a detailed picture of the temporal sequence of these processes, with morphological encoding occurring later than semantic encoding but earlier than phonological encoding (e.g., Janssen, Carreiras, \& Barber, 2011; Strijkers \& Costa, 2011).

Morphological encoding is commonly conceived of as a composition process involved in forming an inflected or derived word form through affixation. A well-known implementation of this idea is the slot-and-fillers model (e.g., Janssen, Roelofs, \& Levelt, 2002), according to which the production of morphologically complex words is supposed to require multiple-slot inflectional or derivational frames for the stem and the affix(es), for which later in the production process phonological codes will be retrieved. One problem of the slot-and-fillers model is that, in order to maintain that different kinds of inflected forms such as walked and sang share the same inflectional frame, 'null morphemes' need to be posited to fill the invisible suffix slot for sang and other irregular forms. However, both from a theoretical linguistic perspective and in terms of a realistic language-production model, the notion of encoding and speaking out null morphemes is not exactly welcome. As an alternative to positing the same slot-and-fillers mechanism for producing all morphologically complex word forms, dual-morphology accounts hold that regular and irregular inflected word forms engage different mechanisms for morphological encoding and production, with irregular forms directly retrieved from memory, and regular forms typically composed from their component parts (stem + affix); see, for example, Pinker and Ullman (2002), Ullman (2004), Clahsen (2006).

As regards children's production of morphologically complex words, the most well-known finding from previous research concerns over-regularization errors, spoken forms such as ${ }^{\star}$ hitted and ${ }^{\star}$ breaked (Marcus et al., 1992) in which the child overapplies the regular past tense to verbs that require irregular forms (hit, broke). Over-regularizations have been intensively studied for different morphological systems and across different languages. The source of children's over-regularization errors is controversial. Some researchers (e.g., Marcus et al., 1992) take over-regularizations as an indication that the child productively applies grammatical rules (Add $-e d$ ). The notion 'rule' in this context is conceived of as an operation over variables, i.e., place-holders that stand for every instance of a given category (Veríssimo \& Clahsen, 2014). Consequently, a rule allows free and unbounded generalization to novel (or unknown) instances, yielding, for example, over-regularizations. An alternative set of approaches denies any reliance on grammatical rules and instead attributes this kind of error to the fact that -ed forms are highly frequent in the child's input, yielding a strong pattern that as such is likely to be (over)used (Bybee, 1995; Elman et al., 1996; Langacker, 2000).

More recently, researchers have begun to use ERPs in order to get a better understanding of processes underlying morphological encoding during children's language production (Budd, Paulman, Barry, \& Clahsen, 2013, 2015; Jessen, Fleischhauer, \& Clahsen, 2017). A methodological challenge for such studies is that muscle activation involved in articulation during overt production may distort the EEG signal (Ouyang et al., 2016). To avoid such artefacts, a delayed vocalization technique has been employed by these studies in which children are prompted to first silently produce the target word form and only thereafter to overtly produce it. This technique provides two sets of data: (i) children's (delayed) overt spoken output 
of a targeted morphologically complex word form, and (ii) the corresponding ERP - time-locked to a silent production cue - to allow insights into the encoding and planning of this word form prior to overt articulation. Using this paradigm, Budd et al. (2013) examined past tense formation in English, Budd et al. (2015) plural forms in English compounds, and Jessen et al. (2017) past participle formation in German. These studies tested seven- to thirteen-year-old children (and adults) and yielded consistent results. For both English and German, children's spoken output was found to be less accurate for irregular than for regular past tense and past participle forms, particularly for the younger children in the sample. The ERPs recorded during children's (silent) morphological encoding and planning of the (correctly inflected) past tense and past participle forms elicited a broadly distributed enhanced negativity for regular (relative to irregular) forms. This brain response - labelled the Morphological Encoding Negativity - has been taken to reflect a control mechanism for regular inflection (to prevent massive overapplication) that is not required for irregular forms; see Clahsen, Budd, Paulmann, and Barry (2018).

\section{Morphological production in bilingual children}

Previous research on bilingual children's production of morphologically complex words has relied on data from elicited production tasks and corpora of spontaneous speech. Studies have focused on inflectional morphology, mostly on grammatical morphemes in English. One common finding from many studies is that the production of inflected word forms appears to be challenging for bilingual children, depending on the children's age of acquisition (AoA), the amount of exposure and use of the languages involved, and cross-linguistic influence between a child's two or multiple languages.

As regards the role of AoA, Meisel (2018), examining grammatical gender in bilingual French/German children, found that children with an age-of-onset of acquisition before 3;6 produce the same constructions, proceed through the same developmental sequences, and attain the same grammatical system as monolingual children. For sequential bilingual children with a later AoA of the second language, this was not the case. Instead, these children were found to produce the kinds of errors typical of adult learners; see Meisel (2008) for similar results on grammatical agreement.

Several studies have focused on the role of exposure and use for bilingual children's grammatical morphology. Differences in amount and quality of input have been claimed to explain more variance in bilingual children's morphological and morphosyntactic skill than AoA. Jia and Fuse (2007), investigating grammatical morphemes of English (3SG, regular and irregular past tense, progressive -ing, BE, and DO) in an elicited production task, found developmental delays for these morphemes in Chinese/English bilingual children and adolescents relative to what is known from monolingual children, concluding that environmental factors were a better predictor for children's attainment in morphology than AoA; see also Blom, Paradis, and Duncan (2012) for a similar conclusion. A large-scale longitudinal study by Paradis, Tulpar, and Arppe (2016) examined bilingual Chinese/English children with respect to a number of grammatical morphemes of English (e.g., 3SG, regular and irregular past tense, BE, and DO). Three of these improved significantly during the first two years and then plateaued (3SG, regular and irregular past tense). At the end of the testing period, after 6;4 years of exposure to English, the mean accuracy 
rate for these grammatical morphemes was around $80 \%$, and 11 out of the 18 children tested did not reach native-like levels. In addition to vocabulary size and short-term memory, environmental factors (e.g., English use at home) were argued to be the most powerful predictors of bilingual children's performance.

In addition to child-internal factors (e.g. AoA) and environmental factors, cross-linguistic influence between a child's two or multiple languages has been suggested as a source of why bilingual children differ from monolingual ones. Blom et al. (2012) argued that rate of development of morphological skill in bilingual children is dependent upon L1 typological properties. For example, Chinese/English and Vietnamese/English bilingual children were found to acquire grammatical morphemes in English more slowly and less accurately (MacDonald, 2000; Jia \& Fuse, 2007; Paradis et al., 2016) than Turkish/English (Marinis \& Chondrogianni, 2010) or Spanish/English (McDonald, 2000) or Punjabi/English (Paradis, 2011) bilingual children. Growing up with English and a fusional language (e.g., Spanish) or an agglutinating one (e.g., Turkish), the child may take advantage of prior knowledge from these languages for learning the grammatical morphemes of English, unlike a child that (in addition to English) grows up with an isolating language such as Chinese or Vietnamese.

As regards the linguistic phenomenon we are examining here, there are (to our knowledge) three previous studies on the topic, i.e., bilingual children's production of regular vs. irregular inflection. Nicoladis, Palmer, and Marentette (2007) examined regular and irregular past tense and past participle forms elicited from 10 French/ English bilingual children, 10 French monolingual, and 10 English monolingual children (age range: 4 to 6 years) in a story (re)telling task. They found that the bilingual children were less accurate than the monolingual children in both languages, in their English for both regular and irregular past tense forms, and in French for irregulars only. The authors attribute the bilingual children's weaker performance to less frequent exposure to either language than monolinguals. Note, however, that the absence of any bilingual-monolingual contrast for regular inflection in French is somewhat mysterious from an exposure-based perspective, as French monolingual children are likely to receive more French input than bilingual ones, not only for irregular but also for regular forms.

Paradis, Nicoladis, Crago, and Genesee (2011) also examined regular and irregular past tense and past participle forms in a larger sample of 23 French/English bilingual children and 21 French monolingual children (age range: 4;1-5;7) using an elicited production task. They found that the bilingual children were less accurate than their monolingual peers with regular and irregular verbs in English, and with irregular (but not with regular) verbs in French, essentially replicating Nicoladis et al.'s (2007) findings. Although Paradis et al. (2011) argue that the observed monolingualbilingual differences are largely attributable to input factors, they also acknowledge that the bilingual children's performance on regular verb forms in French (which is indistinguishable from monolingual children) "is a challenge" (p. 573) from an exposure-based perspective.

Finally, Rispens and de Bree (2015), testing the production of Dutch past tense forms in bilingual Dutch/Hebrew children, found the bilingual children to reach the same high accuracy scores as age-matched monolingual children, but only for the regular past tense. For the production of irregular forms, however, the bilingual children performed significantly below their age-matched monolingual peers, indicating a developmental delay in this particular case. Taken together, what is 
common across these three studies and the languages tested is that the production of irregularly inflected verb forms is less accurate in bilingual (compared to monolingual) children. The results on regular inflection are, however, mixed. Clearly, more research is needed in this domain.

\section{The present study}

The aim of the current study is to contribute to a better understanding of the processes involved in bilingual children's spoken production of morphologically complex words. Our study is the first to report findings not only from their final spoken output of inflected word forms but also from bilingual children's brain measures taken during the encoding and planning of these complex word forms. We tested bilingual (English/ German-speaking) children in both languages, for English on past tense formation and for German on a closely related morphological system, past participle formation. Both types of form are involved in encoding past-time events. The English sentence Ten years ago, I lived in England translates to Vor zehn Jahren habe ich in England gelebt, with the past participle (gelebt) in clause-final position. Both systems have a highly productive regular suffix, $-e d$ in English and $-t$ in German, which for the most common (so-called weak) verbs is combined with the unmarked base stem. In addition, there is a limited lexically restricted class of so-called strong verbs in both languages with irregular past tense and past participle forms. While vowel changes are common for these forms (e.g., broke - gebrochen), past participles of all strong verbs have the ending $-n$ in German, some with and others without stem changes (e.g., treten - getreten 'to hit', brechen - gebrochen 'to break'). In addition, German past participles of verb stems that are stressed on the first syllable have the augment ge-, a prosodic (rather than a morphological) requirement. If a verb stem's primary stress is on a different stem syllable, the past participle form appears without the ge-augment, e.g., verstéhen - verstánden 'to understand - understood[+participle]'.

We employed the materials and procedures from two previous silent-productionplus-delayed-vocalization experiments that tested (seven- to thirteen-year-old) monolingual children - Budd et al. (2013) for English and Jessen et al. (2017) for German - to examine a new group of bilingual (English/German) children of the same age range in both languages. The experiment yielded two sets of data from the bilingual children for each of the two languages: (i) their overt spoken responses of past tense and past participle forms, and (ii) brain potentials during children's encoding and planning of these forms. We ask whether there is a 'bilingual delay/ deficit' with respect to the production of morphologically complex words and the processes involved in morphological encoding. As regards their overt spoken output, this should come with reduced accuracy scores and/or more morphological errors in bilingual (compared to monolingual) children. From previous research, we expect the production of irregular past tense and past participle forms to be particularly affected in bilingual children. With respect to children's ERPs, recall that previous studies with monolingual children have shown that the Morphological Encoding Negativity may be absent in younger children or - if present - has a later onset and/or a longer duration than for older children and adults (Budd et al., 2013; Jessen et al., 2017). Consequently, a developmental delay in bilingual children's morphological encoding should be reflected in the absence of the Morphological Encoding Negativity or in later onsets and/or longer durations of this ERP signature compared to monolingual children. 


\section{Methods}

\section{Ethics statement}

Our study was ethically approved by the University of Potsdam Ethics committee, and parents gave informed written consent before their children completed the study.

\section{Participants}

We tested 69 English/German bilingual children (age range: 8;0-13;11), 33 of them in both languages, 36 children in either English or German. This resulted in 51 datasets for each language. All children were recruited from English/German bilingual schools in Berlin. They had started learning both languages from birth or during early childhood, were all right-handed, had no history of language disorders, and had normal or corrected-to-normal vision. Of the original datasets $(n=102), 23$ had to be excluded because of (i) low overall accuracy rates $(<50 \%)$ in children's overt responses $(n=11)$, (ii) data loss due to technical problems $(n=4)$, and (iii) high artefact rates during the EEG recording $(n=8)$. This led to 79 remaining datasets from 53 children, 41 datasets for English and 38 for German. For 26 of the 53 children we had datasets in both languages. While for 24 of these 26 children there was a considerable time lag between the English and the German test sessions (mean 3.8 months, range: $0.5-12$ months), two children had to be tested in both languages on the same day. From 27 children, we only had data from either English or German. We therefore used a between-participants design and did not directly compare the two languages within the same individual.

To document the children's language history, their parents were asked to fill in a biographical questionnaire which included questions about the languages and their estimated proportions of caretakers' input to the children, which languages the children used to read books, watch TV, listen to audio books, music, and so forth, as well as the languages and their estimated proportions the children used to talk to their family members and friends. The questionnaire data revealed that the group of children we tested had about the same exposure and use of English and German in their daily life.

As regards ENGLISH, the data from 41 bilingual children were analysed. Mean age of acquisition of English was 1.1 years (SD: 1.9). Twenty-two children grew up with English- and German-speaking parents, two children had English/French parents, two children English/Albanian parents, and five children had German and a language other than English at home (e.g., Italian, Dutch, and Russian). ${ }^{1}$ The remaining 10 children had monolingual German parents, but all of them attended bilingual (English/German) nursery schools from age five onwards.

The data from monolingual English speakers we used for comparison come from Budd et al. (2013): 19 adult participants (10 male) with a mean age of 19 years and 4 months, 17 'older' children (5 male) with a mean age of $11 ; 7$, and 20 'younger' children (8 male) with a mean age of $8 ; 6$. All participants were L1 speakers of British English living in southeast England, right-handed, and had normal or corrected-to-normal vision.

Recall that the purpose of the EEG experiment is to determine whether the Morphological Encoding Negativity that Budd et al. (2013) obtained for monolingual

\footnotetext{
${ }^{1}$ It is true that some of the participants were exposed to more than two languages. Here we use the term 'bilingual' as an umbrella term for multilingualism more generally.
} 
English-speaking children can be replicated for bilingual children. To this end, we matched our (older) subgroup of bilingual children to the corresponding one from Budd et al. (p. 347). Our (older) subgroup of bilingual children consisted of 21 bilingual children (14 female) with a mean age of $11 ; 10$, SD: $1 ; 0$. The younger monolingual group tested by Budd et al. did not (yet) show the negativity that was obtained for the older children (and for adults). To avoid replicating a null result and to increase the chances of obtaining the Morphological Encoding Negativity for a second subgroup of bilingual children, we tested 20 bilingual children ( 9 female) with a mean age of $9 ; 5$ (SD: $0 ; 8)$, i.e., children who are on average one year older than Budd et al.'s younger monolingual group.

For German, we included data from 38 bilingual children in the analysis. For these children, the mean age of acquisition of German was 0.5 years (SD: 1.3). Twenty-two children had English- and German-speaking parents, one child had German/Dutch parents, and four children had English and a language other than German at home (French, Albanian, Czech). The remaining 11 children had monolingual parents (10 German, 1 Korean), but all of them attended bilingual (English/German) nursery schools from age five onwards.

The monolingual data we used for comparison come from Jessen et al.'s (2017) study of German L1 speakers: 27 'younger' children with a mean age of 9.44 years (13 girls), 28 'older' children with a mean age of 11.95 (14 girls), and 31 adults with a mean age of 24.34 (27 female). All participants were L1 speakers of Standard German living in the region of Berlin/Brandenburg. They were all right-handed and had normal or corrected-to-normal vision.

As in the case of the bilingual children's English, we also sought to determine for German whether the ERP effect obtained for monolingual German children can be replicated for bilingual children. We therefore subdivided the 38 bilingual children into the same age groups as Jessen et al. (2017, p. 433), an 'older' group with 19 bilingual children (11 female) with a mean age of $11 ; 10$, SD: 1;0, and a 'younger' group with 19 bilingual children (10 female) with a mean age of $9 ; 4, \mathrm{SD}: 0 ; 8$.

\section{Materials}

The ENGLish materials were the same as in Budd et al. (2013): 40 verbs that take a regular past tense form (e.g., walk, henceforth 'R-verbs'), and 40 verbs with an irregular past tense form (e.g., bring, henceforth 'I-verbs'). The I-verbs were closely matched to the $40 \mathrm{R}$-verbs on word (lemma) frequency and on past tense form frequency. All verbs were one syllable long and did not differ significantly regarding number of letters. All items were presented twice, once to elicit the past tense form, and once to elicit the third person singular present tense form. Unlike for the past tense condition, there are no morphological differences between the third person singular present tense forms of I-verbs vs. R-verbs, as both forms are suffixed with $-s$ without any stem changes. Since the same lexical items were tested in the present tense condition, this allows us to determine whether any differences between regular and irregular past tense forms are due to the different lexical items involved. Items were subdivided into two blocks (before and after a break) so that every item showed up only once per block. The order of the blocks was counterbalanced between participants; see Budd et al. (p. 348) for further details.

The GERMAN materials were exactly the same as in Jessen et al.'s (2017) study of monolingual children. There were 100 stems that take regular $(-t)$ participle forms 
(henceforth 'weak verbs'), e.g., lach- 'laugh', and 100 stems that take irregular $(-n)$ participle forms (henceforth 'strong verbs'), e.g., zieh 'pull'. For half of the stems participants were cued to produce the past participle form, for the other half the second person singular present tense (e.g., [du] lachst/ziehst), which served as the control condition. To avoid any effects of stem allomorphy for our experimental materials, we ensured that the targeted verb forms do not require any stem changes in either the present tense or in its past participle form. Jessen et al. selected 30 strong verbs that were matched as closely as possible to 30 weak verbs with respect to length and frequency. To enlarge the sets, twenty verbs in each condition were presented twice to yield 50 items per condition. All stems were one syllable long in all four conditions and did not differ significantly regarding number of letters. As regards frequency, the 50 items of the 'Part_S(trong)' type were closely matched to those of the 'Part_W(eak) type with respect to word-form frequency; see Jessen et al. (pp. 435f) for further details.

\section{Procedure}

The procedure was the same for both languages, and for all children. The experiment took place in a quiet room rented from the Technical University in Berlin. When parents arrived with their children, the experimenter showed them around and explained the experiment. The introduction was followed by electrode set-up. Parents were allowed to stay in the room for the preparation until the experiment started. Parents signed a consent form and filled out the biographical questionnaire. Parents received a small fee (on behalf of their children).

Before the experiment proper, the children were given a short oral explanation of the tasks and an opportunity to ask questions. When it seemed that the children had understood the task, they were asked to read corresponding instructions. If the children had no further questions, the experiment started with 8 practice trials, which were repeated if a child was not feeling comfortable enough to start the experiment.

Items were presented on a 15-inch computer screen using Presentation (version 14.9 07.09.11), positioned approximately $100 \mathrm{~cm}$ apart from participants. All other procedures followed the same as in Budd et al. $(2013,2015)$ and Jessen et al. (2017). Each trial began with a fixation cross at the centre of the screen presented for $100 \mathrm{~ms}$, followed by the infinitive/stem form (e.g., to walk/...sag...) presented in Comic Sans font (96-point) in black on a white background, lasting 1,000ms. The stimulus was followed by a blank screen of varying duration $(250 \mathrm{~ms}, 500 \mathrm{~ms}, 750 \mathrm{~ms})$. After that, one of the two silent-production cues on which the children were previously trained was presented for $2,000 \mathrm{~ms}$, followed by a picture of a loudspeaker, the cue for overtly producing the targeted form presented again for 2,000ms. Each trial ended with a smiley face, presented for $2,000 \mathrm{~ms}$, to indicate the end of trial and the possibility to blink and relax. The experiment itself (for either German or English) had a duration of about 30 minutes, with one break halfway through. The whole procedure, including preparation and training, lasted for about 60 to 75 minutes.

\section{EEG recordings and data analyses}

EEG signals were recorded continuously from 31 electrodes (FP1, FP2, F7, F3, Fz, F4, F8, FC5, FC1, FC2, FC6, T7, C3, Cz, C4, T8, TP9, CP5, CP1, CP2, CP6, TP10, P7, P3, 
$\mathrm{Pz}, \mathrm{P} 4, \mathrm{P} 8, \mathrm{PO} 9, \mathrm{O} 1, \mathrm{O} 2, \mathrm{PO} 10)$ using BrainVision Recorder with active electrodes embedded in an elastic cap (ActiCap). An additional vertical electro-oculogram was applied under the right eye for blink detection. Signals were recorded with an online band pass filter of $0.017 \mathrm{~Hz}$ and $1,000 \mathrm{~Hz}$ and digitized at $500 \mathrm{~Hz}$. Impedances were kept below $20 \mathrm{k} \Omega$ as recommended by ActiCap guidelines. The on-line reference electrode was FCz, but electrodes were off-line re-referenced to the left and right mastoids. Raw data were off-line filtered with $0.5 \mathrm{~Hz}$ high-pass and $30 \mathrm{~Hz}$ low-pass filters. $^{2}$ The data were analysed with BrainVision Analyzer 2.0. Time windows of interest were extracted from $200 \mathrm{~ms}$ before and until $1,200 \mathrm{~ms}$ after the onset of the silent production cue, resulting in $1,400 \mathrm{~ms}$ epochs. Data were baseline corrected using a 200ms pre-stimulus baseline (Tanner, Norton, Morgan-Short, \& Luck, 2016). Only items where children overtly produced correct forms were included. To remove muscle and eye-movement artefacts, an Independent Component Analysis algorithm (Infomax) was applied. Additional artefacts were identified with the semi-automatic artefact rejection option and, if appropriate, were rejected after visual inspection.

All statistical analyses were performed using R (R Core Team, 2012), with the ez package (Lawrence, 2016) or the lme4 package (Bates, Maechler, Bolker, \& Walker, 2014). Accuracy rates were analysed with ANOVAs on the log odds, ${ }^{3}$ with the factors Regularity (regular vs. irregular), Form (past tense/participle vs. present tense), Age Group (older vs. younger children), and Language Group (monolingual vs. bilingual). For the ERP data analysis, we pooled 23 electrodes into 5 regions of interest (ROI): left frontal (LF) (F7, F3, FC5, FC1, C3), right frontal (RF) (F8, F4, FC6, FC2, C4), left posterior (LP) (CP5, CP1, P7, P3, O1), right posterior (RP) (CP6, $\mathrm{CP} 2, \mathrm{P} 8, \mathrm{P} 4, \mathrm{O} 2)$, and midline $(\mathrm{ML})(\mathrm{Fz}, \mathrm{Cz}, \mathrm{Pz})$. Mean amplitudes were extracted, and time windows were selected on the basis of previous studies with monolingual children (Budd et al., 2013; Jessen et al., 2017) - unless specified otherwise. ERP mean amplitudes were analysed using ANOVAs, with the factors Form (present, past), Regularity (irregular, regular), and ROI (LF, RF, LP, RP, ML).

\section{Results}

\section{Behavioural responses: English}

Table 1 presents mean accuracy scores for overt production in the four conditions and the four participant groups. Overall accuracy rates for the bilingual children were high, with considerably lower scores for irregular than regular past tense forms in all participant groups.

In addition to main effects for all four factors (Regularity: $F(1,74)=156.5, p<.001$, Form: $F(1,74)=96.4, p<.001$, Age Group: $F(1,74)=22.3, p<.001$, Language Group:

\footnotetext{
${ }^{2}$ We are aware that a high pass filter of $0.5 \mathrm{~Hz}$ has been claimed to increase the possibility of finding artefacts (Tanner, Morgan-Short, \& Luck, 2015). However, our data are noisier than usual, as testing did not take place in a specially designed EEG lab. Kappenman and Luck (2010, p. 898) pointed out that a high pass filter of $0.5 \mathrm{~Hz}$ yielded the best trade-off between reduction in noise and attenuation of signal for 'high-impedance conditions', under which our data were collected.

${ }^{3}$ The reason for converting the accuracy proportions is that, because proportions are inherently bounded between 0 and 1 and their error variance is not independent from the mean, they may lead to biases in the associated $p$-values. To avoid this, we converted the accuracy proportions to relative odds, which were then subjected to a logarithmic transformation. When this conversion is applied, the scale of the resulting log-odds has the advantageous properties of being unbounded and symmetric around zero, which allows the data to be analysed with ANOVAs.
} 
Table 1. Mean percentages (by subject) of correct responses (and standard deviations) in English for four groups of children

\begin{tabular}{lcccc}
\hline & \multicolumn{1}{c}{ Pres_R } & Pres_I & Past_R & Past_I \\
\hline BIL-Older & 93.3 (SD: 7.0$)$ & 94.2 (SD: 4.8) & 97.3 (SD: 3.1) & 67.7 (SD: 20.0) \\
\hline BIL-Younger & 88.6 (SD: 8.8$)$ & 89.9 (SD: 8.2$)$ & 92.0 (SD: 7.3$)$ & 52.1 (SD: 19.1$)$ \\
\hline MONO-Older* & 96 (SD: 4.7) & 97 (SD: 3.8) & 97.6 (SD: 3.1) & 78.4 (SD: 9.5) \\
\hline MONO-Younger $^{*}$ & 92.75 (SD: 6.7$)$ & 92.5 (SD: 7.4$)$ & 89.25 (SD: 8.6$)$ & 71 (SD: 13$)$ \\
\hline
\end{tabular}

Note. *These data are from Budd et al. (2013).

$F(1,74)=6.3, p=.001)$, the ANOVA revealed interactions of Regularity-by-Language Group $(F(1,74)=7.1, p<.001$, Regularity-by-Form $(F(1,74)=169.9, p<.001)$, and a four-way interaction of Regularity-by-Form-by-Language Group-by-Age Group $(F(1,74)=5.07, p=.003)$. Stepping down by Age Group revealed interactions of Regularity-by-Form for both subgroups (older children: $F(1,36)=95.9, p<.001$; younger children: $F(1,38)=74.1, \quad p<.001)$, and a three-way interaction of Regularity-by-Form-by-Language Group for the younger age group $(F(1,38)=8.7$, $p=.005)$, but not for the older one $(F(1,36)=0.14)$. Stepping down by Form revealed main effects of Regularity for past tense forms in both age groups (older children: $F(1,36)=172.8, p<.001$; younger children: $F(1,38)=110.0, p<.001)$, as well as an interaction of Regularity-by-Language Group for the younger age group $(F(1,38)=11.6$, $p=.002)$, but not for the older one $(F(1,36)=0.35)$. In contrast to past tense forms, there were no significant main effects or interactions for present tense forms. These results are due to (i) larger contrasts between regular and irregular past tense forms in the bilingual than the monolingual children, and (ii) larger contrasts between regular and irregular past tense forms in the younger than the older children, with relatively lower accuracy scores in the irregular past tense condition for the bilingual than for monolingual children and for the younger than the older age groups.

We also analysed the data from the bilingual children separately, using the same factors as in Budd et al.'s (2013) study with monolingual children. For the monolingual children, Budd et al. reported significantly higher overall accuracy scores for the older children (mean age: 11;7) than for the younger ones (mean age: $8 ; 6$ ), and for both age groups, significantly less accurate production of irregular past tense forms than regular past tense forms. As regards the bilingual children, the analysis (on the bilingual children only) revealed (i) a significant effect of Age Group $(F(1,39)=9.0, p=.005)$ and (ii) significant Regularity-by-Form interactions in both Age Groups (older children: $F(1,20)=43.7, p<.001$; younger children: $F(1,19)=74.3$, $p<.001)$. The main effect is due to higher overall accuracy scores for the older than the younger children. The two interactions reflect lower accuracy scores for irregular than for regular past tense forms in both age groups, and even slightly higher accuracy scores for the present tense condition of I-verbs than for those of R-verbs. These findings for bilingual children are in line with those of Budd et al. for monolingual children.

In sum, while the bilingual children showed similar patterns of accuracy scores as the monolingual children, the interactions with Regularity, Form, and Language Group indicate that the bilingual children were less successful in forming correct irregular past tense forms than the monolingual children. This contrast is particularly striking 
for the younger children, as the younger bilinguals were on average a year older than Budd et al.'s (2013) younger monolingual children (mean ages: 9;5 vs. 8;6).

We also examined the ERRORS that bilingual children produced in the irregular past tense condition. The types of error were the same as those reported in previous research with monolingual children (e.g., Marcus et al., 1992): -ed over-regularizations (e.g., ${ }^{\star}$ bringed), lemma errors (e.g., took instead of brought), base-stem repetitions (e.g., bring instead of brought), other (non-past tense) forms (rides instead of rode, or singing instead of sang), and incorrect irregular forms (e.g., ${ }^{\star} b r a n g$ instead of brought). The most common error was -ed over-regularizations. Statistical comparisons revealed that the younger bilingual children's -ed over-regularization rates were significantly higher relative to both those of Budd et al.'s (2013) groups of monolingual children (younger children: $36.75 \%$ vs. $17 \%: F(1,38=19.7, p<.001$ ) and to those of the older bilingual children $(36.75 \%$ vs. $22.9 \%: F(1,39)=5.5, p=.02)$.

Taken together, these results demonstrate less accurate production of irregular past tense forms paired with an increased rate of $-e d$ over-regularizations in bilingual children aged $9 ; 5$, relative both to younger $(8 ; 6)$ monolingual children and to older $(11 ; 7)$ bilingual children. These results are suggestive of a delay in bilingual children's development of the English past tense (compared to monolingual children).

\section{ERP results: English}

In this section, we will report the ERP results from the new datasets of bilingual children in order to determine whether the enhanced negativity during morphological encoding that Budd et al. (2013) obtained from monolingual children can be replicated for bilingual children.

For each bilingual child, mean ERP amplitudes were extracted for each electrode site. For the analysis of the ERP data, we only included trials in which children overtly produced correct English past tense and present tense forms. Of the remaining dataset, the semi-automatic artefact rejection removed a further $13.7 \%$ of datapoints for the younger bilingual group and $4.8 \%$ for the older one. ${ }^{4}$ The grand average ERP waveforms for present tense and past tense forms in the two age groups of bilingual children can be seen in Figures 1 and 2 .

The right panel of Figure 1 displays the waveforms for the older bilingual children in the two critical conditions, which indicates a negative-going waveform elicited when silently producing regular -ed forms relative to irregular ones between approximately $300 \mathrm{~ms}$ and $550 \mathrm{~ms}$. This waveform is most pronounced at right posterior sites. The left panel of Figure 1 compares the waveforms for the present tense control condition in which the same kind of present tense forms (with the $3 \mathrm{sg}$. affix $-s$ ) had to be produced for the two types of verb lemma (R-verbs vs. I-verbs). The left panel of Figure 1 indicates that the negativity for regular past tense forms is not found for the silent production of present tense forms, suggesting that the negativity is unlikely to be due to lexical differences between the different verb lemmas. Figure 2 replicates this pattern of results for the younger group of children. Again, as seen from the waveforms in the right panel of Figure 2, an enhanced negativity over

\footnotetext{
${ }^{4}$ After artefact cleaning and removing trials that elicited incorrect overt responses, the final average number and range of trials in each condition were as follows (out of originally 40 trials per condition): younger children, Pres_R: 31.1 (range 21-39), Pres_I: 30.5 (range 14-40); Past_R: 31.4 (range 19-38), Past_I: 18.1, (range 9-30); older children, Pres_R: 35.9 (29-40), Pres_I: 35.7, (31-40); Past_R: 37.4 (28-40), Past_I: 25.5 (14-40).
} 


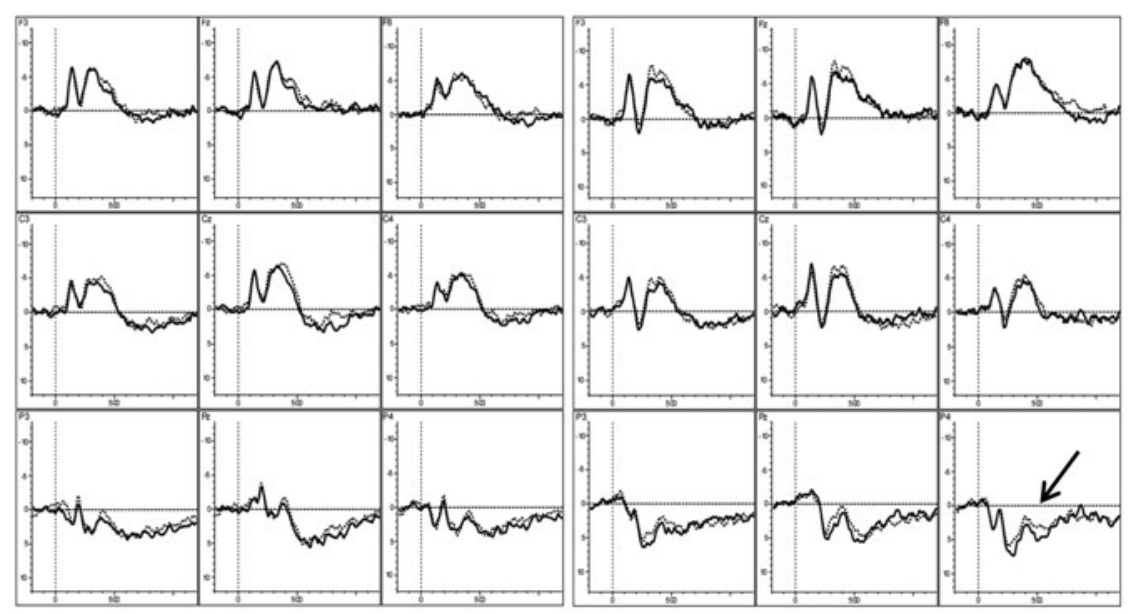

Figure 1. Grand average ERPs for the older bilingual children's production of English present tense (left panel) and past tense forms (right panel). R-verbs (dotted line) are plotted against I-verbs (solid line). Negativity is plotted upwards.

right posterior electrodes is found for regular relative to irregular past tense forms between approximately $300 \mathrm{~ms}$ and $550 \mathrm{~ms}$, but not for R-verbs vs. I-verbs in the present tense condition (left panel).

The statistical analyses confirmed the observations reported above. An ANOVA of the ERP data of the older bilingual children for the 300 to $550 \mathrm{~ms}$ time window (following Budd et al.'s (2013) analysis of the monolingual children's data) revealed a significant main effect of ROI $(F(4,80)=62.4, p<.001)$, a marginally significant effect of Regularity $(F(1,20)=3.5, p=.07)$, and, more importantly, an interaction of ROI-by-Form $(F(4,80)=12.7, p<.001)$. To test for the Morphological Encoding Negativity, planned follow-up analyses by Form and ROI were conducted, which confirmed that the negativity for regular past tense forms (relative to irregular ones) for the right posterior ROI is reliable $(F(1,20)=5.14, p=.03)$, whereas the present tense control condition did not show any significant difference between R-verbs and I-verbs in any ROI (all ps $>.1$ ). There were no other significant contrasts in any other ROI. The same statistical analyses performed on the ERP data of the younger group of bilingual children revealed main effects of Form $(F(1,19)=22, p<.001)$ and ROI $(F(4,76)=54.8, p<.001)$ as well as interactions of Form by Regularity $(F(1,19)=$ $4.6, p=.04)$ and Form by ROI $(F(4,76)=4.1, p=.005)$. Planned follow-up analyses by Form and ROI confirmed a significant negativity for regular over irregular past tense forms (RP: $F(1,19)=5.22, p=.03 ; \mathrm{ML}: F(1,19)=4.46, p=.048$ ), and no corresponding differences for the present tense conditions (all $p s>.1){ }^{5}$

${ }^{5} \mathrm{~A}$ JCL reviewer noted that the signal-to-noise ratio is not the same across our experimental conditions, due to the lower number of trials in the irregular than the regular conditions. This is indeed the case for the English dataset, less so for the German dataset (see footnote 6 below), because particularly the younger children produced quite a few errors in the irregular past tense condition in English, which had to be excluded from the ERP analysis. To address this concern, we redid the ERP analyses of the English ERP data by matching the number of trials in the critical (regular and irregular past tense) conditions within 

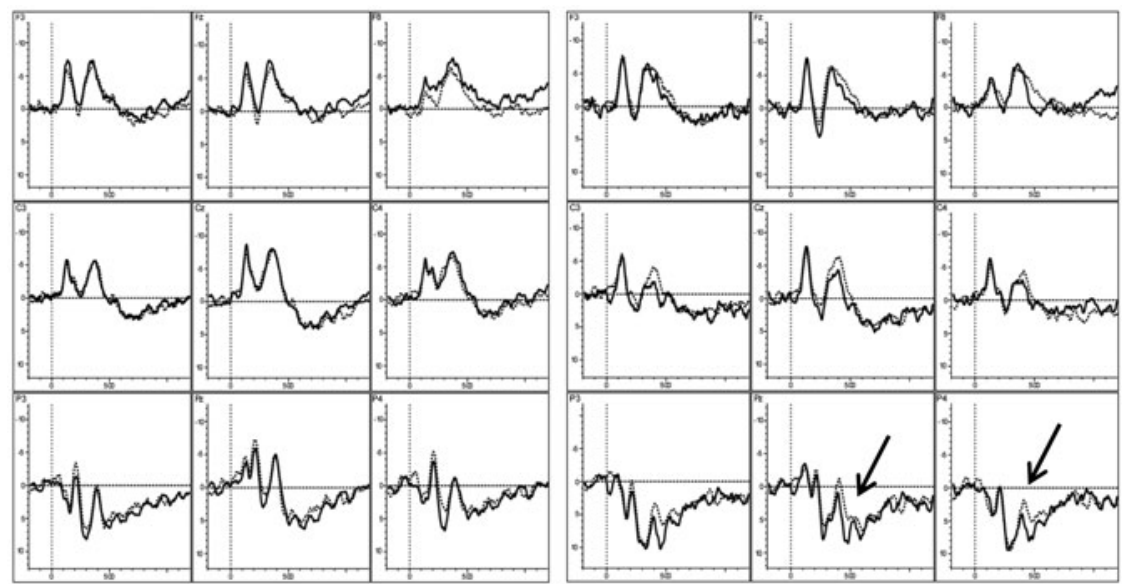

Figure 2. Grand average ERPs for the younger bilingual children's production of English present tense (left panel) and past tense forms (right panel). R-verbs (dotted line) are plotted against I-verbs (solid line).

How do these findings compare with those of monolingual children? Recall that Budd et al. (2013) obtained a significantly enhanced negativity for the production of regular (relative to irregular) past tense forms and no corresponding difference for $\mathrm{R}$-verbs vs. I-verbs in the present tense condition, between $300 \mathrm{~ms}$ and $450 \mathrm{~ms}$ after cue onset in the adult control group, and in the $300-550 \mathrm{~ms}$ time window for the older age group of monolingual children. The effect was broadly distributed in both groups, but was particularly pronounced at right frontal electrode sites in the children. In addition, the production of regular past tense forms (compared to irregular ones) led to a late positivity at left parietal electrodes (P600), for the older child group but not for adults. No significant differences between verb types in either condition were found for the younger monolingual children.

Our ERP data from the bilingual children replicate Budd et al.'s (2013) core finding, viz., the enhanced negativity for the production of regular past tense forms starting at about $300 \mathrm{~ms}$ after the onset of the silent production cue. As illustrated in the topographical maps shown in Figure 3, this negativity has an overall broad distribution in both groups of children, albeit with a right posterior maximum in the bilingual and a right frontal one in the monolingual children. Furthermore, while we obtained the enhanced negativity for both age groups of bilingual children, Budd

participants as closely as possible for both age groups of children. For the older child group, the mean number of trials that went into this additional analysis was 28.6 for the Past-regular (range 14-40) and 25.5 for the Past-irregular (range: 14-40). For the younger child group, the means were 22.7 for the Past-regular (range 9-40) and 18.1 for the Past-irregular (range 9-33). The results of the ERP reanalysis yielded a significantly enhanced negativity for the production of regular over irregular past tense forms in the same time windows as the main analysis, for both age groups (younger children: $F(1,19)=5.07, p$ $=.04$ (midline); $F(1,19)=9.34, p=.006$ (Right posterior); older children: $F(1,20)=6.08, p=.02$ (Right posterior)). These results confirm the Morphological Encoding Negativity obtained in the main analysis. Note also that this ERP effect has been found in a number of previous studies for different morphological phenomena as well as for children and adults. Here, we found this negativity for bilingual children in both their English and German. Taken together, these findings indicate the robustness of the Morphological Encoding Negativity. 


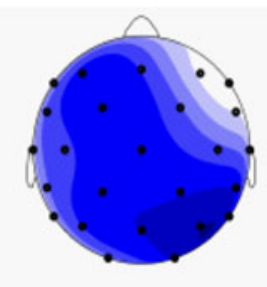

$300 \mathrm{~ms}-550 \mathrm{~ms}$

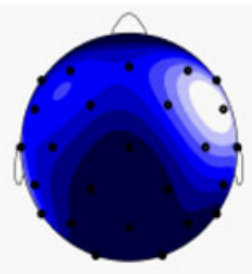

$300 \mathrm{~ms}-550 \mathrm{~ms}$

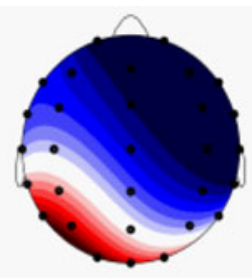

$300 \mathrm{~ms}-550 \mathrm{~ms}$

Figure 3. Topographical maps of the negativity for regular (compared to irregular) past tense forms, depicted for three groups of children. From left to right: BIL-older, BIL-younger, MONO-older; the data from the monolingual speakers come from Budd et al. (2013).

et al. did not find any ERP effect for their younger age group of monolingual children, which is probably due to the fact that the latter were on average a year younger than the former. Finally, the late positivity that Budd et al. additionally found for their older group of monolingual children was not seen for our bilingual children.

\section{Behavioural responses: German}

Table 2 presents mean accuracy scores for the delayed overt production of present tense and past participle forms of verbs that require weak ' $\mathrm{W}$ ' (= regular) or strong ' $\mathrm{S}$ ' (= irregular) participle forms in German. Overall accuracy rates for the older age groups were higher than for younger ones, amongst both the bilingual and the monolingual children.

The ANOVA revealed main effects of Form $(F(1,89)=19.96, p<.001)$ and Age Group $(F(1,89)=32.1, \quad p<.001), \quad$ as well as a significant interaction of Regularity-by-Form $(F(1,98)=12.2, p<.001)$ and a marginally significant interaction of Form-by-Age Group $(F(1,98)=3.5, p=.06)$. These results reflect similar patterns of accuracy scores for bilingual and monolingual children. The main effect of Age Group confirms that accuracy scores improve for older children (relative to younger ones), in both the bilingual and the monolingual groups. The main effect of Form is due to overall lower scores for the participle (relative to the present tense) conditions. The (marginally significant) Form-by-Age Group interaction reflects smaller differences between accuracy scores for participle than for present tense forms in the younger than the older age groups. More importantly, the significant Regularity-by-Form interaction is due to better accuracy scores for regular ('weak') than for irregular ('strong') participles, and lower accuracy scores for present tense forms of weak than for those of strong verbs, a pattern that is again found for both monolingual and bilingual children.

We also analysed the data from the bilingual children separately, as did Jessen et al. (2017) for the monolingual children. For the latter, Jessen et al. reported higher overall accuracy scores for the older than the younger children and a main effect of 'Condition', which was due to reduced accuracy rates for the production of irregular ('strong') participles. As regards the bilingual children, the ANOVA revealed a main effect of Age Group $(F(1,36)=4.4, p=.04)$ and an interaction of Regularity-by-Form which was significant for the older child group $(F(1,18)=6.3, p=.02)$ but not for the 
Table 2. Mean percentages (by subject) of correct responses (and standard deviations) in German for four groups of children

\begin{tabular}{lcccc}
\hline & Pres_W & Pres_S & Part_W & Part_S \\
\hline BIL-Older & 87.9 (SD: 8.2$)$ & 90.9 (SD: 8.1$)$ & 83.3 (SD: 13.1$)$ & 80.4 (SD: 14.8$)$ \\
\hline BIL-Younger & 76 (SD: 18.2) & 82 (SD: 18.4$)$ & 77.5 (SD: 13.7$)$ & 76.6 (SD: 11.5$)$ \\
\hline MONO-Older* & 90.6 (SD: 11.7$)$ & 92.1 (SD: 9.7$)$ & 90.2 (SD: 7.9$)$ & 89.6 (SD: 9$)$ \\
\hline MONO-Younger $^{*}$ & 77.2 (SD: 15.1$)$ & 77.6 (SD: 14.8$)$ & 77.8 (SD: 11.4$)$ & 74.9 (SD: 13.6$)$ \\
\hline
\end{tabular}

Note. *These data are from Jessen et al. (2017).

younger one $(F(1,18)=1.9, p=.2)$. These results are due to higher overall accuracy scores for the older than the younger children and higher accuracy scores for regular than for irregular participle forms, particularly in the older child group. These findings for our bilingual children are similar to those of Jessen et al. for monolingual children.

Finally, we examined the kinds of error overtly produced by the bilingual children in the irregular ('strong') participle condition, in comparison to the monolingual children's errors. Jessen et al. (2017) reported that the two age groups of monolingual children rarely produced genuine morphological errors, viz. $-t$ over-regularizations for strong verbs, but that other non-morphological errors (null responses and lexical errors) were more common. In the bilingual data, however, the most common error type in the participle-strong condition were $-t$ over-regularizations. Furthermore, between-group comparisons revealed that $-t$ over-regularization rates were significantly higher for the bilingual than the monolingual children in both age groups (older children: $4.3 \%$ vs. $11.2 \%: F(1,45)=8.7, p=.005$; younger children: $6.6 \%$ vs. $13.5 \%: F(1,44)=11.5, p=.001)$.

Summarizing, we found that the bilingual children's accuracy scores were overall high and similar to those of monolingual German-speaking children of the same age, but that the bilingual children produced more morphological errors, viz. - $t$ over-regularizations than the corresponding age-equivalent monolingual children.

\section{ERP results: German}

As for English, we will examine the German ERP data with respect to whether the Morphological Encoding Negativity that Jessen et al. (2017) obtained for monolingual children can be replicated for bilingual children.

The analyses of the German ERP data were parallel to those of the English data. We extracted mean ERP amplitudes and excluded all trials with incorrect past participle and present tense forms. For the German data, the semi-automatic artefact rejection removed a further $9.1 \%$ for the younger bilingual group and $4.8 \%$ for the older one. ${ }^{6}$ The grand average ERP waveforms for present tense and participle forms in the two age groups of bilingual children are shown in Figures 4 and 5.

For the older group of bilingual children, Figure 4 (right panel) shows a more negative-going waveform for the production of regular (weak) over irregular (strong)

\footnotetext{
${ }^{6}$ For German, the final average number and range of trials in each condition were as follows (out of originally 50 trials per condition): younger children, present tense weak: 35.2 (range 14-42), strong: 37.8 (range 19-48), participle weak: 35.3 (range 15-46), strong: 33.7 (range 12-45); older children, present tense weak: 41.9 (21-48), strong: 43.4, (20-50), participle weak: 39 (19-49), strong: 38.7 (16-48).
} 


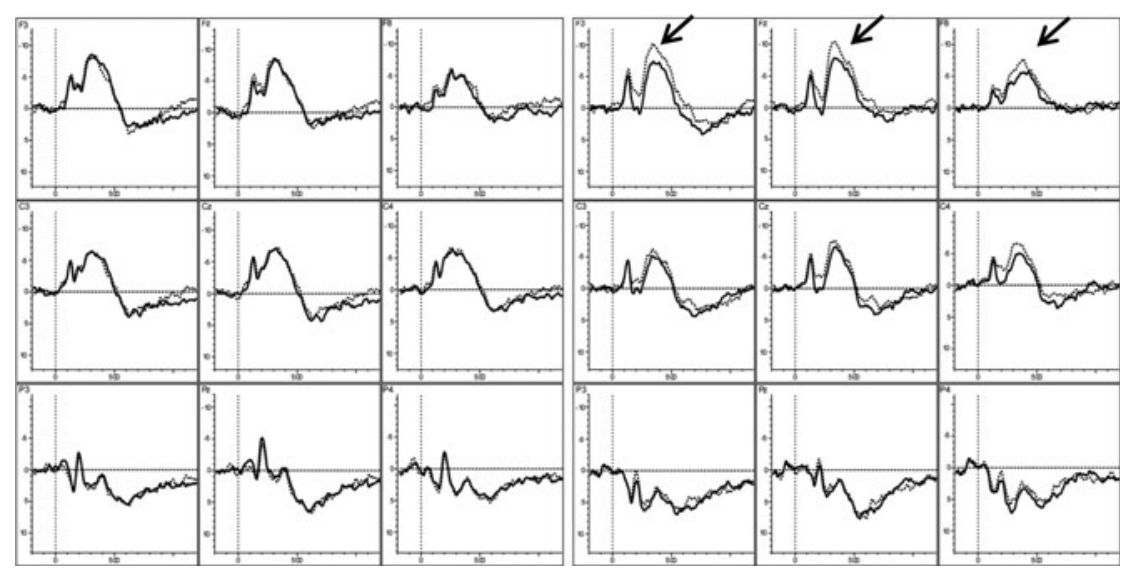

Figure 4. Grand average ERPs for the older bilingual children's production of German present tense forms (left panel) and participle forms (right panel). W(eak)-verbs (dotted line) are plotted against S(trong)-verbs (solid line).

participle forms from approximately 300 to $550 \mathrm{~ms}$ which was most pronounced over frontal electrodes. For the present tense control condition (left panel, Figure 4), there was no corresponding difference between the waveforms for regular (weak) over irregular (strong) verbs. For the younger group of bilingual children, Figure 5 (right panel) again indicates a more negative-going waveform for the production of regular (weak) over irregular (strong) participle forms with a maximum at right-frontal electrode sites, albeit with a delayed onset $(700-800 \mathrm{~ms})$ relative to the older children. For the production of present tense forms, there were again only minimal differences between the waveforms associated with the two verb types (Figure 5, left panel).

We performed the same statistical analyses as for the English ERP data. For the ANOVA of the older bilingual children, we selected the same time window (300 to $550 \mathrm{~ms}$ ) as did Jessen et al. (2017) for their older monolingual group. This analysis yielded a significant main effect of ROI $(F(4,72)=57.7, p<.001)$ and an interaction of ROI-by-Form $(F(4,72)=6.28, p<.001)$, as well as a main effect of Regularity $(F(1,18)=3.43, p=.08)$ and interactions of Regularity-by-ROI $(F(4,72)=2.14, p=.08)$ and Form-by-Regularity $(F(1,18)=3.41, p=.08)$, the latter of which were marginally significant. Subsequent analyses split up by Form and ROI revealed a significantly enhanced negativity for regular compared to irregular participles in frontal regions (LF: $F(1,18)=4.97, p=.04$; RF: $F(1,18)=7.63, p=.01)$, marginal at midline (ML: $F(1,18)=4.02, p=.06)$. For the present tense conditions, on the other hand, there were no corresponding differences (all $p s>.1$ ).

For the younger bilingual children, the $800-1,000 \mathrm{~ms}$ selected by Jessen et al. (2017) for their younger monolingual group did not yield any significant main effects or interactions. Nevertheless, the ERP data from the younger bilingual children (see Figure 5) indicates a more negative-going waveform for regular (irregular) participles in a slightly earlier time window (viz., $700-800 \mathrm{~ms}$ ). We therefore performed exploratory analyses for the younger bilingual children for this $(700-800 \mathrm{~ms})$ time window, which resulted in a significant main effect of ROI $(F(4,72)=5.9, p<.001)$ and interactions of ROI-by-Regularity $(F(4,72)=2.52, p=.048)$ and of ROI-by-Form 


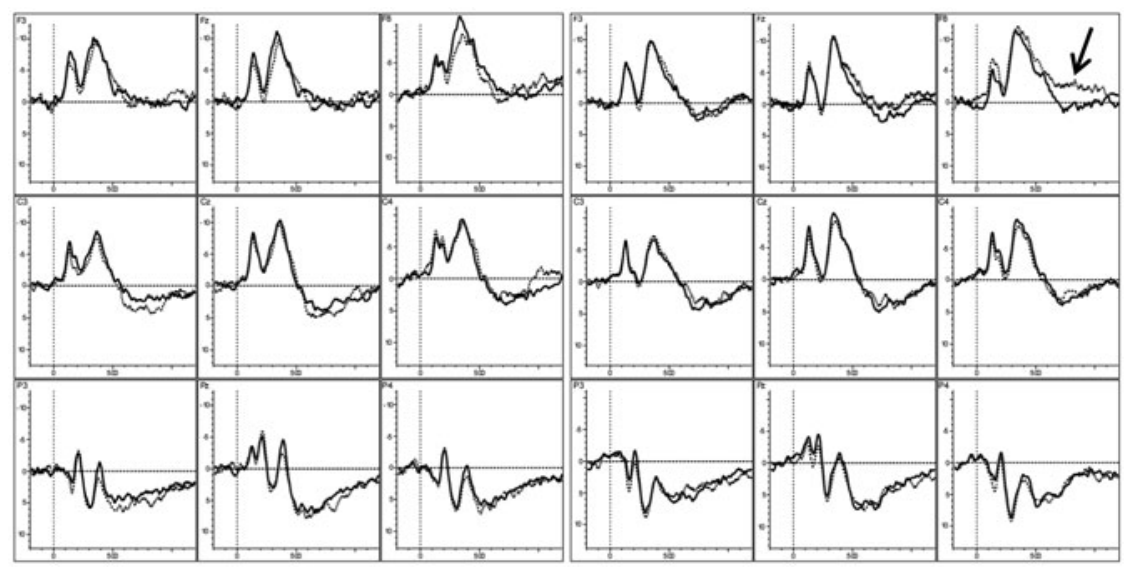

Figure 5. Grand average ERPs for the younger bilingual children's production of German present tense forms (left panel) and participle forms (right panel). W(eak)-verbs (dotted line) are plotted against S(trong)-verbs (solid line).

$(F(4,72)=2.12, p=.08)$, the latter only marginally significant. Further stepping down by Form and ROI confirmed a significantly enhanced negativity for regular (weak) participles relative to irregular (strong) ones in the right-frontal region $(F(1,18)=$ 4.42, $p=.049$ ), and no corresponding difference between these verb types in the present tense condition $(F(1,18)=1.0, p=.8)$.

The new set of ERP data from the bilingual children shows the enhanced negativity for the production of regular participle forms that Jessen et al. (2017) obtained for German child and adult L1 speakers, with the same polarity and a delayed onset latency in the younger (relative to the older) children. In Jessen et al.'s data, the negativity was broadly distributed in the two groups of (monolingual) children, compared to the more focal negativity seen for adults. In the bilingual child groups, this negativity also had an overall broad distribution, but with a right-frontal maximum (unlike the more posterior maximum for the monolingual children); see Figure 6 for illustration.

\section{Discussion}

The current study reports the first ERP study of bilingual children's encoding and spoken production of morphologically complex words. We found that the ERP signature for morphological encoding that was previously obtained in monolingual children (viz. the 'Morphological Encoding Negativity') could be replicated for bilingual children. On the other hand, the same bilingual children's spoken output contained more morphological errors relative to age-equivalent monolingual children. Here, we offer an account of these findings from a dual-morphology perspective.

\section{Competition in morphological encoding and production}

Dual-morphology models posit two routes from conceptual encoding towards spoken production, one that involves the retrieval of lexical entries of (typically irregularly) 


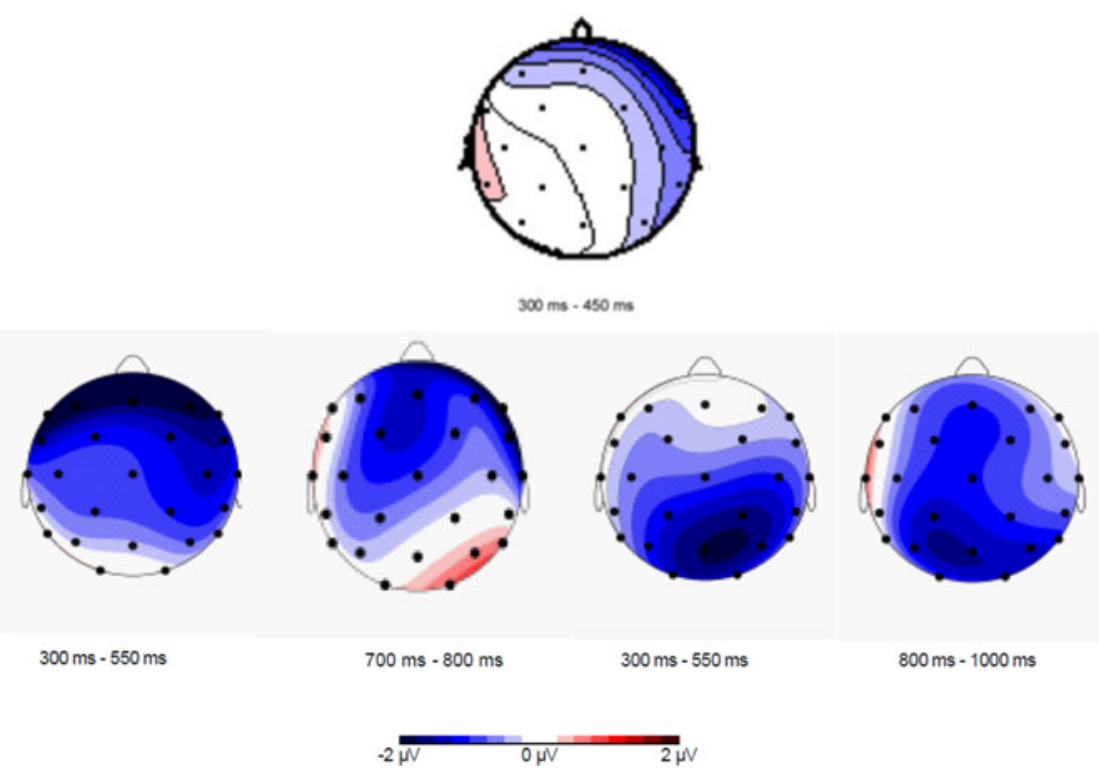

Figure 6. Topographical maps of the negativity for regular (compared to irregular) participle forms, depicted for adult L1 speakers (top) and four groups of children (bottom). From left to right: BIL-older, BIL-younger, MONO-older, MONO-younger; the data from the monolingual speakers come from Jessen et al. (2017).

inflected forms from memory, and another one that engages computational processes to generate (typically regularly) inflected forms from stems and affixes. The question then arises of how the two routes compete with each other in language production and how their outputs can be constrained. Consider the two inflectional systems under study here, past tense formation in English and past participle formation in German, for which one of the competitors functions as a default that applies 'elsewhere', in cases in which a particular verb does not have its own past tense or participle form. These highly productive regular morphological processes ('Add -ed' in English, 'Add - $t$ ' in German) need to be constrained so that they do not over-generate, yielding incorrect output such as ${ }^{\star}$ breaked (instead of broke) or ${ }^{\star}$ geschlaft (instead of geschlafen 'slept'). A model sketching how this may work for the production of English past tense forms is shown in Figure 7; see also Pinker and Ullman (2002) and Clahsen et al. (2018).

The model illustrated in Figure 7 assumes two routes for producing morphologically complex words, a look-up component for retrieving (irregular) forms stored in lexical memory and a rule-based component for forming productive (regular) inflected word forms. The output of the lexical look-up component is unconstrained. Once a specific entry is found, this entry is submitted to the speech output system and articulated, for example, /tvk/ for the verb to take (Figure 7a). By contrast, accurate production of a regular past tense form (Figure $7 \mathrm{~b}$ ) requires an additional constraint to check whether for a given candidate form (e.g., walked) there is no equivalent stored form that would block the regular form. This constraint can be conceived of as a control process or output filter prior to phonological encoding. Consider first the current ERP results on morphological encoding in the light of this model. 
(a)

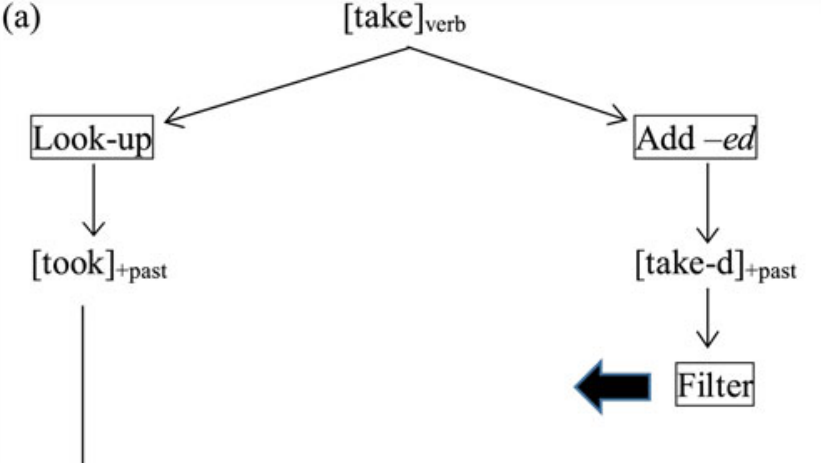

/tuk/

(b)

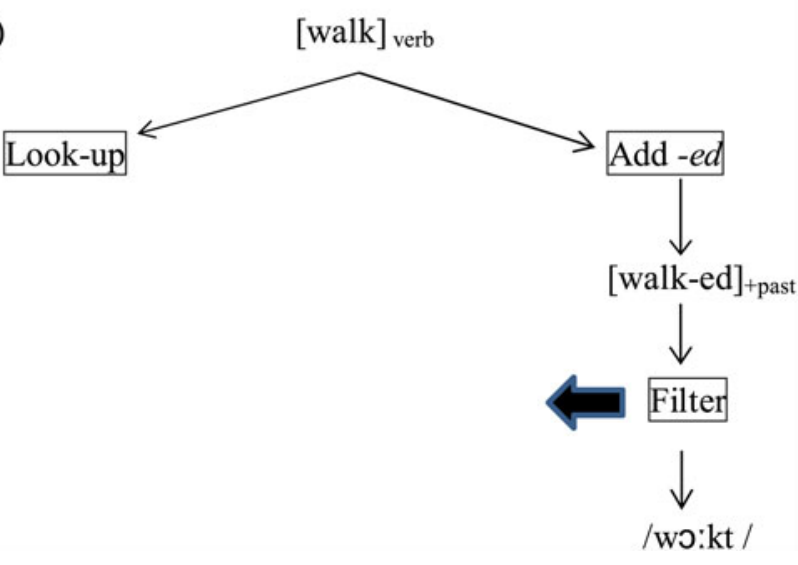

Figure 7. A schematic representation of the production of English past tense forms.

\section{Competition during morphological encoding}

We replicated for bilingual children an ERP effect (viz. the Morphological Encoding Negativity) that was previously found for monolingual children and adults (Budd et al., 2013, 2015; Festman \& Clahsen, 2016; Jessen et al., 2017; Clahsen et al., 2018). This ERP effect was found for different morphological systems (past tense / past participle inflection, plurals inside compounds, comparative adjective formation), in different languages (English, German), and for different populations, viz. child and adult native speakers, non-native (adult L2) speakers, and in the current study for bilingual children. ${ }^{7}$ A range of morphological exponents including both inflectional affixes and periphrastic forms have been found to elicit the Morphological Encoding

\footnotetext{
${ }^{7}$ It is true that regular past participles are on average shorter than irregular ones in German. Note, however, that in English regular past tense forms are on average LONGER (at least in terms of letters) than irregular ones, because of the suffix -ed. Yet, we found similar brain responses in the German experiment and the English experiments, for both monolingual and bilingual participants. We therefore do not think that the Morphological Encoding Negativity is due to word length differences.
} 
Negativity, i.e., the past tense -ed in English, the past participle $-t$ in German, the plural $-s$ in English (compounds), and the analytic (more) comparative form in English (e.g., more neutral). Despite these differences in formal spell-out, these diverse phenomena share one core property in that they all involve a highly productive grammatical process (e.g., 'Add-ed') that competes with lexically restricted ('irregular') forms and needs to be prevented from overapplication. Hence, what is common to all these phenomena in terms of the model shown in Figure 7 is that accurate production of these forms is subject to an additional control/filter process prior to phonological encoding, a constraint that is not required for producing corresponding forms (e.g., the irregular past tense forms) that are directly retrieved through lexical look-up.

Furthermore, it is noteworthy that the Morphological Encoding Negativity is reminiscent of fronto-central negativities occurring in similar time windows $(\sim 300-$ $800 \mathrm{~ms}$ ) which have been taken to reflect processes involved in conflict monitoring and cognitive control (e.g., Patel \& Azzam, 2005; Folstein \& Van Petten, 2008). It is therefore conceivable that this ERP effect is not specific to grammatical morphology (or language) but is instead part of a family of negativities that signal cognitive control processes more generally (see Clahsen et al., 2018).

\section{Developmental considerations on morphological encoding}

Whilst the same enhanced negativity was found for adult L1 and adult L2 speakers' production of $-e d$ past tense forms in English (Festman \& Clahsen, 2016), developmental differences were seen between children and adults. Budd et al. (2013) obtained, for example, an additional P600 (on top of the enhanced negativity) in their monolingual child L1 group that was not found for adults, which they interpreted as signalling "additional resources that children (relative to adults) require for morphologically encoding regularly inflected word forms" (p. 353). Similarly, in Budd et al.'s (2015) study, the enhanced negativity was delayed in the children relative to adults $(800-900 \mathrm{~ms}$ vs. $300-450 \mathrm{~ms}$ post-cue). Budd et al. (2015) interpreted these differences as indicating that morphological processing in children is less efficient and more resource-demanding. Finally, Jessen et al. (2017) reported developmental differences between L1 child and L1 adult speakers with respect to the latency of the Morphological Encoding Negativity, with this ERP effect having a longer duration in children than in adults and the onset of the negativity being substantially delayed in the younger child group compared to the older children and adults. Jessen et al. attributed these differences to brain maturation, assuming neuroanatomical changes in eight- to twelve-year-old children that are supposed to lead to more efficient neuronal communication (Casey, Galvan, \& Hare, 2005; Blakemore, 2012).

Consider the current ERP results for bilingual children from a developmental perspective. As for the English ERP data, although the enhanced negativity was seen for monolingual children, adults, and bilingual children, the additional late positivity (possibly reflecting the engagement of additional processing resources) was found for monolingual children, but not for bilingual children and for adults. Regarding the German ERP data, whilst the enhanced negativity from monolingual children was again replicated for our group of bilingual children, the negativity had an earlier onset for the younger bilingual than the monolingual children. Hence, given these findings and the account of the child-to-adult developmental changes proposed by Budd et al. (2013) and Jessen et al. (2017), our current ERP findings suggest that 
bilingual children are more advanced and/or engage fewer resources for morphological encoding than monolingual children of the same age. This suggestion also fits in with the possibility that the ERP effect we obtained here for morphological encoding may reflect conflict monitoring and cognitive control more generally, as these are cognitive processes on which bilingual children are supposed to have an advantage over monolingual children (Poarch \& van Hell, 2012). While these considerations are admittedly speculative, we can safely conclude that our ERP data disconfirm the notion of a bilingual delay with respect to morphological encoding.

\section{Competition and morphological errors in children's spoken output}

The second main finding of the current study is that bilingual children produced significantly more morphological errors on verbs requiring irregular forms than their monolingual peers, in line with results from previous studies (Nicoladis et al., 2007; Paradis et al., 2011; Rispens \& de Bree, 2015). A likely source for their morphological errors is that the entries for irregular forms have reduced activation levels and/or connections to their base forms in the bilingual children's mental lexicon. Consequently, the output generated by the lexical look-up route is less reliable and not strong enough to block the output of the competing grammatical route; see Figure $7 \mathrm{a}$ for illustration. As a result, over-regularizations of $-e d$ past tense and $-t$ participle formation in English and German respectively, are more common in bilingual than in age-matched monolingual children. That bilingual children may have weaker lexical representations has been attributed to the fact that they receive less input in each of their languages and use them less often than children growing up with just one of these languages (Gollan, Montoya, Cera, \& Sandoval, 2008, among many others). This account of 'weaker links' which has originally been proposed for the associative networks amongst simplex lexical items (e.g., Michael \& Gollan, 2005) may very well extend to the lexical representations of irregular word forms and the links to their base forms.

\section{Conclusion}

The question of whether or not the development of linguistic skills in each of a bilingual child's languages lag behind those of monolingual children has received considerable attention from both bilingualism researchers and the public, and has still not received a clear answer. The present study investigated bilingual children's production of morphologically complex words, processes involved in both morphological encoding/planning and the final spoken output. We found that morphological encoding (during silent production) elicited an ERP effect in both the bilingual children's English and German that has previously been reported for monolingual children. Thus, the ERP data clearly disconfirm the notion of a bilingual delay. If anything, on some measures, the bilingual children's ERP patterns appeared to be more advanced than those of age-matched monolingual children. Nevertheless, their spoken output contained considerably more morphological errors ('over-regularizations') in both their languages than corresponding monolingual children performing the same (elicited-production) task.

We conclude that bilingual children's language production does indeed lag behind that of monolingual children, IN SOME RESPECTS. Recall that the kinds of morphological systems we examined invoke both grammatical computation (for encoding and 
producing regularly inflected word-forms) and access to entries (for irregular forms) stored in lexical memory, and that memory retrieval is known to be particularly sensitive to frequency of exposure and use. From this perspective, bilingual children's reduced exposure to each of their languages (relative to monolingual children) causes at best a SELECTIVE DELAY in bilingual children, which affects irregular forms. Crucially, however, grammatical computation and the mechanisms of morphological encoding were not found to be delayed in bilingual children.

Author ORCIDs. (D) Harald Clahsen, 0000-0002-6190-1318

Acknowledgements. This work was supported by an Alexander-von-Humboldt-Professorship awarded to Harald Clahsen. We thank Andy Plante-Kropp and Kate Stone for help with the data collection.

\section{References}

Bates, D., Maechler, M., Bolker, B., \& Walker, S. (2014). lme4: linear mixed-effects models using Eigen and S4. R package version 1.1-7. Online https:/github.com/lme4/lme4/ http://lme4.r-forge.r-project.org/.

Bialystok, E. (2009). Bilingualism: the good, the bad, and the indifferent. Bilingualism: Language and Cognition, 12(1), 3-11.

Bialystok, E. (2017). The bilingual adaptation: how minds accommodate experience. Psychological Bulletin, 143(3), 233-62.

Blakemore, S.-J. (2012). Imaging brain development: the adolescent brain. Neuroimage, 61(2), $397-406$.

Blom, E., Paradis, J., \& Duncan, T. S. (2012). Effects of input properties, vocabulary size, and L1 on the development of third person singular $-\mathrm{s}$ in child L2 English. Language Learning, 62(3), 965-94.

Budd, M.-J., Paulmann, S., Barry, C., \& Clahsen, H. (2013). Brain potentials during language production in children and adults: an ERP study of the English past tense. Brain and Language, 127(3), 345-55.

Budd, M.-J., Paulmann, S., Barry, C., \& Clahsen, H. (2015). Producing morphologically complex words: an ERP study with children and adults. Developmental Cognitive Neuroscience, 12, 51-60.

Bybee, J. (1995). Regular morphology and the lexicon. Language and Cognitive Processes, 10(5), 425-55.

Carroll, S. E. (2017a). Exposure and input in bilingual development. Bilingualism: Language and Cognition, 20(1), 3-16.

Carroll, S. E. (2017b). Explaining bilingual learning outcomes in terms of exposure and input. Bilingualism: Language and Cognition 20(1), 37-41.

Casey, B., Galvan, A., \& Hare, T. A. (2005). Changes in cerebral functional organization during cognitive development. Current Opinion in Neurobiology, 15(2), 239-44.

Clahsen, H. (2006). Dual-mechanism morphology. In K. Brown (Ed.), Encyclopedia of language and linguistics (Vol. 4, pp. 1-5). London: Elsevier.

Clahsen, H., Budd, M.-J., Paulmann, S., \& Barry, C. (2018). Morphological encoding beyond slots and fillers: an ERP study of comparative formation in English. PLoS One 13(7), e0199897. doi.org/ 10.1371/journal.pone.0199897

Elman, J., Bates, E., Johnson, M., Karmiloff-Smith, A., Parisi, D., \& Plunkett, K. (1996). Rethinking innateness: a connectionist perspective on development. Cambridge, MA: MIT Press.

Festman, J., \& Clahsen, H. (2016). How Germans prepare for the English past tense: silent production of inflected words during EEG. Applied Psycholinguistics, 37(2), 487-506.

Folstein, J. R., \& Van Petten, C. (2008). Influence of cognitive control and mismatch on the N2 component of the ERP: a review. Psychophysiology, 45(1), 152-70.

Gollan, T. H., Montoya, R. I., Cera, C., \& Sandoval, T. C. (2008). More use almost always means a smaller frequency effect: aging, bilingualism, and the weaker links hypothesis. Journal of Memory and Language, 58(3), 787-814.

Grosjean, F. (2010). Bilingual: life and reality. Cambridge, MA: Harvard University Press.

Hoff, E., Core, C., Place, S., Rumiche, R., Señor, M., \& Parra, M. (2012). Dual language exposure and early bilingual development. Journal of Child Language, 39(1), 1-27.

Indefrey, P., \& Levelt, W. J. (2004). The spatial and temporal signatures of word production components. Cognition, 92(1/2), 101-44. 
Janssen, D. P., Roelofs, A., \& Levelt, W. J. (2002). Inflectional frames in language production. Language and Cognitive Processes, 17(3), 209-36.

Janssen, N., Carreiras, M., \& Barber, H. A. (2011). Electrophysiological effects of semantic context in picture and word naming. Neuroimage, 57(3), 1243-50.

Jessen, A., Fleischhauer, E., \& Clahsen, H. (2017). Morphological encoding in German children's language production: evidence from event-related brain potentials. Journal of Child Language, 44(2), $427-56$.

Jia, G., \& Fuse, A. (2007). Acquisition of English grammatical morphology by native Mandarin-speaking children and adolescents: age-related differences. Journal of Speech, Language, and Hearing Research, 50 (5), 1280-99.

Kappenman, E. S., \& Luck, S. J. (2010). The effects of electrode impedance on data quality and statistical significance in ERP recordings. Psychophysiology, 47(5), 888-904.

Kupisch, T. (2018). Introduction: recent developments in early bilingualism. Bilingualism: Language and Cognition, 21(4), 653-5.

Langacker, R. (2000). Grammar and conceptualization. Berlin: de Gruyter.

Lawrence, M. A. (2016). ez: easy analysis and visualization of factorial experiments. R package version 4.4-0. Online <https://CRAN.R-project.org/package $=$ ez $>$.

Luk, G., Green, D. W., Abutalebi, J., \& Grady, C. (2012). Cognitive control for language switching in bilinguals: a quantitative meta-analysis of functional neuroimaging studies. Language and Cognitive Processes, 27(10), 1479-88.

Marcus, G. F., Pinker, S., Ullman, M., Hollander, M., Rosen, T. J., Xu, F., \& Clahsen, H. (1992). Overregularization in language acquisition. Monographs of the Society for Research in Child Development, i-178.

Marinis, T., \& Chondrogianni, V. (2010). Production of tense marking in successive bilingual children: When do they converge with their monolingual peers? International Journal of Speech-Language Pathology, 12(1), 19-28.

McDonald, J. L. (2000). Grammaticality judgments in a second language: influences of age of acquisition and native language. Applied Psycholinguistics, 21(3), 395-423.

Meisel, J. M. (2008). Child second language acquisition or successive first language acquisition. In B. Haznedar \& E. Gavruseva (Eds.), Current trends in child second language acquisition (pp. 55-80). Amsterdam: John Benjamins.

Meisel, J. M. (2013). Sensitive phases in successive language acquisition: the critical period hypothesis revisited. In C. Boeckx \& K. Grohman (Eds.), The Cambridge handbook of biolinguistics (pp. 69-85). Cambridge University Press.

Meisel, J. M. (2018). Early child second language acquisition: French gender in German children. Bilingualism: Language and Cognition, 21(4), 656-73.

Michael, E. B., \& Gollan, T. H. (2005). Being and becoming bilingual. In J. Kroll \& A. M. B. de Groot (Eds.), Handbook of bilingualism: psycholinguistic approaches (pp. 389-407). Oxford University Press.

Nicoladis, E., Palmer, A., \& Marentette, P. (2007). The role of type and token frequency in using past tense morphemes correctly. Developmental Science, 10(2), 237-54.

Ouyang, G., Sommer, W., Zhou, C., Aristei, S., Pinkpank, T., \& Rahman, R. A. (2016). Articulation artifacts during overt language production in event-related brain potentials: description and correction. Brain Topography, 29(6), 791-813.

Paradis, J. (2011). Individual differences in child English second language acquisition: comparing child-internal and child-external factors. Linguistic Approaches to Bilingualism, 1(3), 213-37.

Paradis, J., Nicoladis, E., Crago, M., \& Genesee, F. (2011). Bilingual children's acquisition of the past tense: a usage-based approach. Journal of Child Language, 38(3), 554-78.

Paradis, J., Tulpar, Y., \& Arppe, A. (2016). Chinese L1 children's English L2 verb morphology over time: individual variation in long-term outcomes. Journal of Child Language, 43(3), 553-80.

Patel, S. H., \& Azzam, P. N. (2005). Characterization of N200 and P300: selected studies of the event-related potential. International Journal of Medical Sciences, 2(4), 147-54.

Pinker, S., \& Ullman, M. T. (2002). The past and future of the past tense. Trends in Cognitive Sciences, 6 (11), 456-63. 
Poarch, G. J., \& van Hell, J. G. (2012). Executive functions and inhibitory control in multilingual children: evidence from second-language learners, bilinguals, and trilinguals. Journal of Experimental Child Psychology, 113(4), 535-51.

R Core Team (2012). R: A language and environment for statistical computing. R Foundation for Statistical Computing, Vienna, Austria. Online <https://www.R-project.org/>.

Rispens, J., \& de Bree, E. (2015). Bilingual children's production of regular and irregular past tense morphology. Bilingualism: Language and Cognition, 18(2), 290-303.

Strijkers, K., \& Costa, A. (2011). Riding the lexical speedway: a critical review on the time course of lexical selection in speech production. Frontiers in Psychology, 2, 356. doi.org/10.3389/fpsyg.2011.00356

Tanner, D., Morgan-Short, K., \& Luck, S. J. (2015). How inappropriate high-pass filters can produce artifactual effects and incorrect conclusions in ERP studies of language and cognition. Psychophysiology, 52(8), 997-1009.

Tanner, D., Norton, J., Morgan-Short, K., \& Luck, S. J. (2016). On high-pass filter artifacts (they're real) and baseline correction (it's a good idea) in ERP/ERMF analysis. Journal of Neuroscience Methods, 266, $166-70$.

Ullman, M. T. (2004). Contributions of memory circuits to language: the declarative/procedural model. Cognition, 92(1/2), 231-70.

Veríssimo, J., \& Clahsen, H. (2014). Variables and similarity in linguistic generalization: evidence from inflectional classes in Portuguese. Journal of Memory and Language, 76, 61-79.

Cite this article: Clahsen H, Jessen A (2019). Do bilingual children lag behind? A study of morphological encoding using ERPs. Journal of Child Language 46, 955-979. https://doi.org/10.1017/S0305000919000321 